科 学 通 报

\title{
活性氧和黄腐酸使软骨细胞分泌 蛋白多糖异常*
}

李宏强许善锦 常淑云王 苝

(北京医科大学无机教研室, 北京 100083)

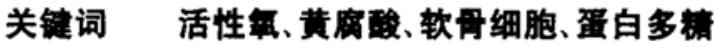

关节软骨是一种没有血管、没有神经的组织, 软骨细胞代谢物的转运要通过基质、并依赖 于基质的结构和组成. 蛋白多糖 (Proteoglycan, PG) 的含量是控制软骨性能的一个重要参 数, 即使有微小的变化也会导致组织行为的改变. 活性氧能不同程度地损伤氨基多糖 (Glycasaminoglycan; GAG) 和 PG, 而黄腐酸 (Fulvic acid, FA) 不能直接降解 GAG 和 PG. 为进一步探讨大骨节病区 FA 和活性氧在大骨节病病理过程中的作用, 我们研究了 FA 和活 性存在时, 体外培养的鸡胚肢软骨细胞分泌 PG 的组成变化和异常 PG 对差基磷灰石 (Hydroxyapatite, HAP) 晶体生长的影响, 并与 5- 溴 - $2^{\prime}$ - 脱氧尿甘 (5-Bromo-2'-deoxyuridine, 5-Brdurd) 对软骨细胞的作用进行了比较, 以探寻活性氧和软骨细胞去分化之间的相关性.

\section{1 材 料 和 方 法}

\subsection{HAP 的制备}

按 Nancollas ${ }^{[1]}$ 的方法合成 HAP, 产物经红外光谱和化学分析证明为结晶度较好的 HAP 晶体.

\section{2 软骨细胞培养 ${ }^{[2]}$}

在无菌条件下取出已化 12 天的鸡胚, 分离出长肢骨, 将能端软骨切成小块, 用 $0.25 \%$ $(W / V)$ 肤蛋白酶消化, 洗涤, 在生长液中 (1640 培养基, 含小牛血清和抗坏血酸) 轻轻吹打, 分散 细胞, $(8.0 \pm 0.5) \times 10^{5}$ 细胞 $/ \mathrm{ml}$ 接种培养, 每两天换液或加人实验因子一次 $\left(1.0 \times 10^{4} \mathrm{U} / \mathrm{ml}\right.$ 黄 嘌呤氧化酶 $(X O D)-1.0 \times 10^{-4} \mathrm{~mol} / \mathrm{L}$ 次黄嘌呤 $(\mathrm{HX}) 、 30 \mathrm{ppm}$ FA 或 $\left.30 \mathrm{ppm} 5-\mathrm{Brdurd}\right)$, 从第 二天起分别收集培养液, $-20^{\circ} \mathrm{C}$ 保存备用.

\section{3 培养液中 PG 的提取与纯化}

收集好的各组培养液按 $0.38 \mathrm{~g} / \mathrm{ml}$ 加人固体盐酸胍, 同时使溶液中含 $0.1 \mathrm{~mol} / \mathrm{L} 6$ - 氨基已 酸、 $5 \mathrm{mmol} / \mathrm{L}$ 芐㜆盐酸盐, $5 \mathrm{mmol} / \mathrm{L}$ EDTA, $0.1 \mathrm{mmol} / \mathrm{L}$ 苯甲磺酰第. $4^{\circ} \mathrm{C}$ 搅拌 $24 \mathrm{~h}, 12000 \mathrm{r} / \mathrm{min}$ 离心 $30 \mathrm{~min}$, 弃去沉降物, 上清液按文献[3] 处理. 最后浓缩, 冷冻干燥得 PG 固体.

1993-06-28 收稿, 1993-09-24 收修改稿.

“国家“八五”科技攻关基金资助项目. 


\section{4 不同实验因子存在时软骨细胞分泌 PG 的组成分析}

以葡萄糖醛酸为标准系列测定糖醛酸的含量 ${ }^{[4]}$, 并由此推算出硫酸软骨素 (Chondroitin sulfate, Chs) 的含量; 以 Chs 为标准系列测定总 GAG 的含量 ${ }^{[5]}$; 以无水硫酸钠为标准系列测 定硫酸基的含量 ${ }^{[6}$, 由于 PG 单体中只含 Chs 和硫酸角质素 (Keratin sulfate, KS), 所以, KS 的 含量可由 GAG 的含量减去 Chs 的含量求得. 各含量均用质量百分比浓度表示.

\subsection{PG 对 HAP 成长过程的影响}

取 $5.003 \times 10^{-3} \mathrm{~mol} / \mathrm{L}$ 磷酸二氢钾贮备液 $5.00 \mathrm{ml}$ 于夹层恒温反应器中, 加人去离子水 35.0 $\mathrm{ml}$, 通氮气保护, 电磁摚拌, 加人 $1.0 \mathrm{~mol} / \mathrm{L}$ 氯化钾溶液 $5.00 \mathrm{ml}$, 调 $\mathrm{pH}$ 值为 7.4 , 加人 $\mathrm{PG}$ 样品 $2.0 \mathrm{mg}$, 待完全溶解后加人 $9.917 \times 10^{-3} \mathrm{~mol} / \mathrm{L}$ 氯化钙咜备液 $5.00 \mathrm{ml}$, 调 $\mathrm{pH}$ 值为 7.4 , 恒定 $\mathrm{pH}$ 值 $30 \mathrm{~min}$ 后, 加人 HAP 晶种 $2.0 \mathrm{mg}$, 立即开始计时, 用自动电位滴定计自动滴加氢氧化钾溶 液 $(0.0104 \mathrm{~mol} / \mathrm{L})$, 记录不同时间消耗氢氧化钾溶液的体积 $\left(V_{\mathrm{KOH}}\right)$, 以 $V_{\mathrm{KOH}}$ 对时间作图即为 HAP 生长的动力学曲线. 平衡后用 $0.2 \mu \mathrm{m}$ 的微孔滤膜滤出固体, 水洗, 晾干, 真空干燥后在 扫描电镜下观察固体的表面形态.

\section{2 结 果与 讨 论}

\section{1 不同实验因子作用下软骨细胞分泌 PG 的组成分析 (表 1)}

体外培养的软骨细胞表型 (Phenotype) 是不稳定的, 许多因子都能诱导软骨细胞去分化 (Dedifferentiate) 为成纤维样细胞 (Fibroblastic cell), 表现为细胞变大, 脆性增加, 并由圆形变 为梭形[], 细胞中蛋白质/DNA 比值增加, II 型胶原蛋白的 mRNA 水平大幅度降低 ${ }^{\left[{ }^{[}\right.}$, 细胞趋 于合成 I 型胶原蛋白, 这时 PG 的合成减少. 5-Bradurd 可能掺人 DNA 内代替胸腺嘧啶的位 置, 干扰基因表达, 诱导软骨细胞去分化 ${ }^{[9]}$. 活性氧是生物体内氧代谢的活性中间体, 能损伤 许多重要的生物大分子和小分子, HX-XOD 体系主要产生超氧阴离子 $\left(\cdot \mathrm{O}_{2}^{-}\right)$(也有人认为此 体系的活性成分主要是 $\left.\mathrm{H}_{2} \mathrm{O}_{2}^{[10]}\right)$, 它能损伤软骨细胞, 使软骨细胞畸变为梭形或多角形 ${ }^{[11]}$, 并刺 激软骨细胞合成 I 型胶原蛋白 ${ }^{[12]}$, 从这些表现特征来看, 活性氧与软骨细胞去分化具有一定相 关性. 已知病区 FA 具有半醌自由基信号, 在大骨节病的病理过程中, 我们认为 FA 是通过自 由基机理起作用的. 与本文表 1 中的对照组相比, 加人实验因子后各组细胞分泌的 PG 中硫 酸基和总 GAG 的百分含量减少, 硫酸化程度下降, 而 $\mathrm{KS} / \mathrm{Chs}$ 的比值有所增加, 其中 HX-XOD 组 PG 中的硫酸基和总 GAG 含量减少最明显,而 5-Brdurd 组细胞分泌 PG 中的总 GAG 变 化不明显, 但 KS/Chs 的比值显著升高. 可见各实验因子与软骨细胞作用时, 软骨细胞分泌 PG 的组成变化趋势相似, 但程度各异, 这些变化是否一定是软骨细胞去分化的结果, 有待进一步 研究.

表 1 不同实验因子作用下软骨细胞分泌 PG 的组成分析

\begin{tabular}{cccccccc}
\hline 实验因子 & 糖醛酸 (\%) & 硫酸基 (\%) & GAG(\%) & Chs(\%) & KS(\%) & KS/Chs & 硫酸基/GAG \\
\hline 对 照 & 16.30 & 7.46 & 72.04 & 41.14 & 30.87 & 0.749 & 0.104 \\
HX-XOD & 7.02 & 2.13 & 37.95 & 17.73 & 20.22 & 1.140 & 0.056 \\
FA & 8.52 & 3.86 & 47.04 & 21.52 & 25.52 & 1.186 & 0.082 \\
BrdUrd & 10.40 & 6.87 & 69.77 & 26.27 & 43.50 & 1.656 & 0.098 \\
\hline
\end{tabular}




\subsection{PG 对 HAP 生长动力学的影响}

从图 1 可以看出, 各种实验因子作用下软骨细胞分泌的 PG 均能抑制 HAP 晶体的生长, 但以 HX-XOD 体系作用组软骨细胞分泌的 PG 抑制效果最弱, 平衡时固相结晶度最差, 表

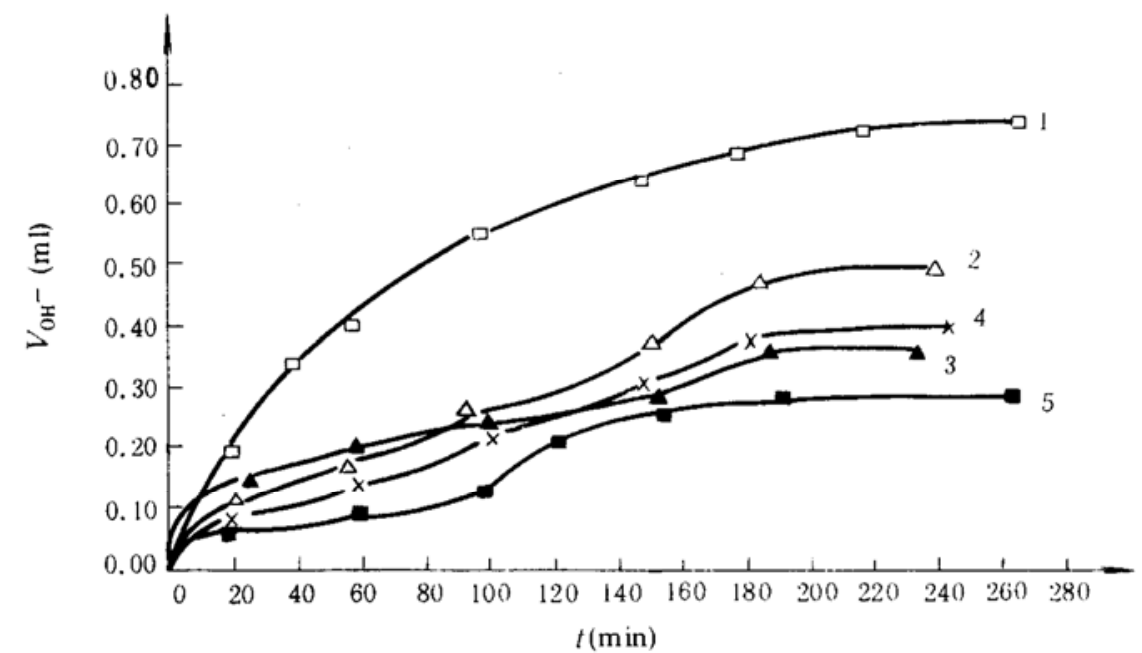

图 1 不同来源 PG 对 HAP 晶体生长的影响

1 - 无 PG, 2 - HX-XOD 组 PG, 3- FA 组 PG, 4-5-BrdUrd 组 PG, 5一对照组 PG

面附生小晶体较多. 这里至少有两方面原因, 一方面 PG 和 GAG 可以吸附在 HAP 表面, 阻滞 (block) 晶体表面的活性成核部位, PG 中 GAG 的百分含量降低, 则相同量 PG 所能覆盖的活 性位点数减少, 即抑制效应减弱; 另一方面 $\mathrm{PG}$ 上的 $-\mathrm{OSO}_{3}^{-}$和 $-\mathrm{COO}^{-}$带负电荷, 由于同种电荷 之间的推斥作用维持了 PG 伸展的空间结构,表现出妨碍离子运动的立体位阻. 硫酸化程度降 低, 则电荷与电荷之间的相互作用减弱, 立体位阻随之变小, 使溶液中钙和磷酸根离子向晶体表 面迁移的速度加快. Chen ${ }^{[13]}$ 曾详细研究了硫酸基对生物矿化的影响, 发现脱去硫酸基的 Chs 和右 旋糖苷对 HAP 生长的抑制能力弱于未脱硫酸基的 Chs 和右旋糖苷, 这与本文观点一致.

\section{参考文糔}

[1] Nancollas, G. H. et al., Arch. Oral Biol., 1970, 15:731.

[2] 王维哲等, 中国地方病学杂志, 1982, 1(4): 271.

[3] Antonopoulos, A. C. et al., Biochim. Biophys. Acta, 1974, 338: 108.

[4] Bitter, T. et al., Anal. Biochem., 1962, 4:330.

[5]张惟杰主编, 复合多㴋生化研究技术, 上海科学技术出版社, 1989, 301.

[6] Antonopoulos, A. C.,' Acta Chem. Scand., 1962, 6: 1521.

[7] Chacko, S. et al., J. Exp. Med., 1969, 130:417.

[8] Finer, M. H. et al., Mol. Cell Biol., 1985, 5(6): 1415.

[9] Mayne, R. et al., Exp. Cell Res., 1984, 151:171.

[10] Link, E. M. et al., Biochem. J., 1988, 249:391.

[11] 张法浩等, 北京医科大学学报, 1989, 21(6): 593 .

[12] 张法浩等, 北京医科大学学报, 1990, 22(1): 59 .

[13] Chen, C. C. et al., Calcif. Tissue Int., 1985, 37: 395. 